\title{
Suggestions for the Development of Thai Music in Entertainment Venues to Promote Tourism in Phuket
}

\author{
Teerathorn Lamnaokrut ${ }^{1,3}$, Songkoon Chantachon ${ }^{1} \&$ Marisa Koseyayothin ${ }^{2}$ \\ 1 The Faculty of Cultural Science, Mahasarakham University, Khamriang Sub-District, Kantarawichai District, \\ Maha Sarakham Province, Thailand \\ ${ }^{2}$ Kanchanapisek Non-Formal Education Centre (Royal Academy), Salaya Sub-District, Bhuttamonthon District, \\ Nakhon Pathom Province, Thailand \\ ${ }^{3}$ Prince of Songkla University, Phuket Campus, Amphur Kathu, Phuket, Thailand \\ Correspondence: Teerathorn Lamnaokrut, The Faculty of Cultural Science, Mahasarakham University, \\ Khamriang Sub-District, Kantarawichai District, Maha Sarakham Province 44150, Thailand. E-mail: \\ lamnaokrutt120@gmail.com
}

Received: April 29, 2014 Accepted: May 29, 2014 Online Published: June 12, 2014

doi:10.5539/ach.v6n2p139 URL: http://dx.doi.org/10.5539/ach.v6n2p139

\begin{abstract}
This qualitative research uses observation, interview and focus group discussion to study the background and problems of Thai music ensembles in Phuket, so to make suggestions for their development. The research findings reveal that since the city shifted from tin-mining to tourism, Thai music has been used to welcome tourists. There are three problems in the Thai music business: a) problems with Thai music troupes; b) problems with places where Thai music is performed; and c) problems with tourists. The main cause of the problems is a lack of effective cooperation between Thai music ensembles and their employers. The research makes five suggestions for musical adaptations: 1) Thai music and folk music, 2) Thai and Western music, 3) Thai music and sounds, 4) Thai music and performances, and 5) music from CDs and performances. These adaptations must preserve cultural roots so that they will not compromise the identity of Thai music.
\end{abstract}

Keywords: Thai music, adaptation, tourism, entertainment venues, Phuket Province

\section{Introduction}

Performance art is an extension and representation of lifestyle. Embodied within is the local wisdom of the past that has been inherited from experience and imagination through human feelings and emotion. Belief systems are also passed on through performance art, as well as strategies for teaching people how to behave and act. This is a branch of art that responds to mental needs and demonstrates the beautiful culture of people in different areas. Performance art is imitation of nature through the use of creative emotion to communicate and indicate identity of people in different areas. Aside from this, performance art is also a mode of inheritance for feelings, emotions and concepts. Performance arts can refer to original art or adaptations, including drama, music and indigenous performance, which communicate meanings and stories and connect the feelings, emotions and thoughts of the performers with their audience so that the viewers may understand that which is being presented. Therefore, performance art is one part of human culture that derives from the lifestyle of people in the area in order to communicate the different stories of the past to the present generations. Thai music is therefore a part of cultural heritage that reveals the essence of being Thai and has just as much value as other aspects of social culture in the world.

\subsection{The Importance of Thai Music for the Tourism Industry}

Sangobseug Tamwihan (1997) found that Thai music holds great and important benefit regarding aesthetics in cultural heritage, the essence of being Thai, the essence of being a Thai person and the delicate and subtle moods of the ancestors. One of the characteristics of Thai music is relaxation, which corresponds to the research of Chanit Pugan (2006), who considered Thai music as refreshing in a comparatively peaceful and gentle manner. Pugan compared Thai music to a trickle of water that travels from altitude to the world below, creating a fine spray of mist that relaxes and calms all people that come into contact with it. Music is a product of the behavior of human creative thinking but that behavior itself derives from human perceptions of the surrounding 
environment in which they live. The study of creating musical understanding depends on social culture and unavoidable human encounters with time and place.

If considered in this way, music only responds to needs of aesthetic pleasure, but this perspective is insufficient. It is actually necessary to consider the role, importance and meaning of music in the society. There must be differences between different societies and the level of development in each society (Wallipokom, 1992). There are many types of music, as in other forms of culture. One type is contemporary music that has been rapidly developed worldwide to high levels of advancement. Another type is the natural form of the original music. Whether in the same country or culture, the progression of musical styles are not equal because the roles and concepts of music creation in each society are different in terms of knowledge, understanding, popularity and the promotion of objectives, positive factors, necessity and social class (Rungrueang, 2004).

Thai music is another part of culture that gives the community an opportunity to use their cultural funds to create presentations to add value to the economy, build occupations and income for the community and use as tools for development of the community and area, as well as the nation. This is all facilitated by the national identity found in music that draws the interest of tourists. The most necessary aspect of the inheritance of Thai musical identity in the field of tourism is the preparation of data regarding the form of cultural performance to show cultural tourist audiences so that they better understand the traditions, customs and lifestyle of people in the area. Therefore, areas of high tourism will cooperate in the systematic collection of cultural data and classify the data so that it is ready to present to tourists. Currently, commercial management of Thai musical performance responds well to tourist demands, particularly regarding Thai eating establishments, national theaters that show acting performances to transmit the national artistic culture and tourist hotels, from one star to five, which use Thai music to relax their guests and support cultural tourism. If it is possible to use Thai music to provide various tourism services, it will increase jobs within Thai musical performance. This is a way to support and promote the Thai music profession and encourage inheritance from generation to generation in order to generate income and develop the knowledge of Thai music in the wider community.

\subsection{Tourism and Culture in Thailand}

The fourth quarter of the Thai economic outlook of 2009-2010 by the Office of the National Economic and Social Development Board to promote the Gross Domestic Product concluded that tourism clearly recovered from a previous lull, especially in December when 1.63 million tourists visited the country, a $40.8 \%$ increase. This was the largest number of visiting tourists in the year and brought the total number of visitors in the fourth quarter to 4.2 million people, an increase of $26.2 \%$. The majority of tourists came from China, Korea and Taiwan and the number of people staying in hotels increased to $54.6 \%$ from $49.6 \%$ the previous year, causing the hotel and restaurant and communications and transportation businesses to increase by $13.5 \%$ and $6.9 \%$, respectively. For the whole year there were 14.1 million tourists, which was a higher figure than the target of 14.0 million people (RYT9, 2010)

Modern tourists like to search for knowledge, experience and understanding in the local culture and lifestyle, which are increasingly the end objective of travel. The desire is to increase familiarity with the area and its people. There is also increased popularity in travel for study and this increases the importance of cultural heritage. The 2007 Constitution of Thailand, article 289 stipulated that it was the responsibility of Thai people to pursue training in protection, conservation and inheritance of their beautiful national culture, including important local wisdom (Office of the National Human Rights Commission of Thailand, 2007). The Ministry of Culture aims to operate according to four strategies in response to the constitutional responsibilities, which are: a) maintenance of national culture and strengthening of local cultural variety; b) creation of value regarding imagination and local Thai wisdom; c) use of Thai cultural funds to add value to society and add economic value; d) manage religious, artistic and cultural knowledge through the cooperation of affiliated institutions, which are The Office of the Undersecretary of the Ministry of Education, The Fine Arts Department, Department of Religious Affairs, Office of the National Culture Commission, Office of Contemporary Art and Culture and Princess Maha Chakri Sirindhorn Anthropology Centre (Ministry of Culture, 2013). The work of these organizations is aimed to generate success for the people and nation according to the strategies of the Ministry of Culture by using the national culture budget to create social value and add economic value. This counts as an opportunity that will make Thailand a country with high cultural funding and variety and enable existing funds to be used to create value and generate income by process, management and format of presentation varieties.

\subsection{Research Context}

Phuket Province is the only Province in the country composed entirely of islands. It is a world renowned tourist attraction known for its beautiful beaches and seas that are suitable for diving. In the past, the majority of wealthy people in Phuket were Chinese miners and rubber tradesmen. The Chinese influence is visible in the 
Chinese spirit houses that are scattered around the city and the world-famous festival of the Nine Emperor Gods, which is held every October. When the quantity of tin on Phuket decreased, the tourism business replaced the role of mining. As Phuket has many beautiful natural resources, tourists started to visit the Province, causing its tourist industry to develop with the help of domestic and international funding. This caused the majority of wealthy mining entrepreneurs to shift their focus to the tourism business and led to the continuous development of the tourism industry, which has resulted in the economic prosperity of modern-day Phuket.

Phuket is the largest island in Thailand and a province in the South of the country, located off the Western coast of the country in the Andaman Sea, part of the Indian Ocean. There are also thirty-seven outlying islands that make up the province. The area of Phuket Province is $570.30 \mathrm{~km}^{2}$; of which $543.034 \mathrm{~km}^{2}$ belong to Phuket Island. Phuket Island is $21.3 \mathrm{~km}$ wide (from East to West) and $48.7 \mathrm{~km}$ long (from North to South). It takes approximately twelve hours to travel to Phuket by car from Bangkok and about one hour by plane. Government in Phuket is divided into three districts, seventeen sub-districts and one-hundred and seven villages. Administration is controlled by the Phuket Provincial Administration Organization and six Municipalities (Poomputaworn). Phuket is a province that places primary importance upon the tourism industry, as the basic income of the province comes from this route. Thai musical performance is used by tourist industry businesses such as restaurants, shops and hotels, especially four and five star hotels. Thai music is played throughout the year and generates constant work and income for performers. Other attractions also use Thai musical performances, but not to a large extent; only during important festivals because there are not enough funds. Consequently, the majority of Thai musical performers mainly finds work in the large hotels and supplements this with any other work they can find. The hotels use Thai musical performance as a selling point and a point of attraction for tourists, which causes the artists to become popular with tourists in Phuket. This also helps the performers generate an income. Thai music is thus one form of Thai culture that is important for tourism in Phuket and attracts many visitors each year.

Nowadays, the success of the Thai music culture in Phuket tourism has caused many artists to migrate from different provinces and seek work. This has created four problems with Thai music in Phuket Province: a) lack of knowledge regarding administration and management, causing the reduction of fees; $b$ ) lack of loyalty to a group and frequent defection to musical ensembles offering higher wages and better treatment; c) lack of knowledge in performance art, causing performances to divert from the original customs towards modern styles; d) lack of Thai musical knowledge development and development of creativity and ability of the individual performers to remain equal to the international community, resulting in social inequality. These problems are causing the Thai music profession to decline and the performers are unable to increase the level of their quality of life. For this reason, the employers are able to gain advantage over the Thai music performers by only thinking about tourist numbers, rather than considering the influence and disadvantage for the Thai musical culture. These attitudes fall in line with the provincial policy of drawing maximum numbers of visitors to the province by using Thai art as part of the plan, yet lack support and development of the Thai musicians' quality of life in line with the development of tourism.

From the data given in this introduction, the researchers were interested in studying the use of Thai music in entertainment venues to support tourism in Phuket. If it is possible to help promote the commercial administration business of Thai music and increase networking, the community will improve and there will be a revolution in the level of funding and developmental support for the performing arts profession. Additionally, the quality of life of artists in Phuket will be raised, Thai culture will be supported and there will be value in the inheritance of performing arts for the future. This research therefore aims to study the background and problems of Thai musical ensembles in entertainment venues in Phuket in order to make suggestions for improving the current situation.

\section{Research Methodology}

This qualitative research was conducted using documentary study and field research.

\subsection{Research Area}

Phuket Province was selected as the research area based on its renown as a cultural tourist destination. From the data collected by the Phuket provincial tourist office, the research area within the province was selected using a purposive sampling technique. The research sample consisted of nine ensembles (including the group leaders, musicians and performers) and related individuals (employers from entertainment venues using Thai musical performance, culture and tourism experts, cultural administrators, community leaders, the tourism and sports office of Phuket, local mass media and domestic and international tourists). There were three informant groups, totaling ninety-five individuals: key informants, consisting of thirty-five people from four groups - nine 
ensemble leaders, fifteen experts in Thai musical art and tourism, five cultural administrators and six community leaders; casual informants, consisting of twenty people from two groups - fifteen ensemble members and five people with jobs related to the Thai music profession; general informants, consisting of forty people from two groups - ten employers from tourist entertainment venues and thirty tourists (ten Thai, ten from the greater Asia region and ten from Europe).

\subsection{Research Method}

The tools used for data collection consisted of basic survey, participant and non-participant observation, structured and non-structured interview, focus group guidelines and workshop. Secondary data was collected from related entertainment venues, books, meeting notes, research papers and articles, investigations and the Internet to understand about the social and culture environment, theories and concepts in sociology and humanities and information and history of the research area. Primary data was collected using field study in the research area by observation, interview and focus group discussion. Data was collected and categorized into groups according to the method of collection (documentary study and field research) and according to the research aims. This data was then verified and validated using investigator triangulation and the methodological triangulation of Denzin, which is an assessment of the credibility of data collected from different sources (Jantawanit). The data was then analyzed in accordance with the research aims and consistent with the theories of Supang Jantawanit (2003), by using analytic induction and typological analysis. The results are here presented as a descriptive analysis.

\section{Research Results}

\subsection{The History of Thai Music Ensembles at Entertainment Venues in Phuket Province}

Thai music ensembles at entertainment venues in Phuket Province originated with the performances of Ajarn Trussada Chanyon, who held acting performances in hotels around Patong Beach to employ and give practice opportunities for his students. Thai music thus began to flourish in the area from 1982 as tourist entertainment venues supplemented their service to entertain and enhance the cultural knowledge of tourists. This gave Thai music a role in the tourist service. Later, when the hotel business in Phuket expanded, different hotels employed music ensembles to work at their establishments. Ensembles from outside the area were required to satisfy demand as there were not enough local groups to meet the needs of the entertainment venues. With the high employment and income opportunities, migrating musicians invited their friends and family to follow and create their own ensembles. From these beginnings, new ensembles were formed. Originally, the first new ensembles were made by people from the Central Region of Thailand, such as Bangkok and similar provinces (Pathum Thani, Suphanburi, Ang Thong and Sukhothai). These areas were home to musical education institutions and artists with high quality and standards. Moreover, employment opportunities in Central Thailand were few, due to the high concentration of ensembles based in the area, giving musicians a reason to travel to find work. The groups reached Phuket and have remained since.

Nowadays, there are over ten Thai music ensembles to be found in Phuket, yet only a few have systematic management and planning and are trusted to perform regularly at different entertainment venues. The nine ensembles that fall into this category are: 1) Trussada Entertainment, established in 1982 by Ajarn Trussada Chanyon; 2) Ban B Saeng Tabtim, established in 1987 by Anong Saeng Tabtim; 3) Leulak Entertainment, established in 2002 by Wittikorn Chamnan; 4) Thai Heritage. Established in 2002 by Ajarn Utorn Singkaew; 5) Ban Tontri Sano, established in 2003 by Boonlert Tontri Sano; 6) Samai Thai, established in 2007 by Pairat Srihone; 7) Passorn Entertainment, established in 2008 by Passorn Fakfueang; Siraporn Tawatit, established in 2008 by Ajarn Nattawit Boonmee Meechai; 9) Rak Thai, established in 2011 by Urarat Songsirisombat. These nine ensembles have direct performance experience and the members come from all regions of Thailand. Ensembles that do not have regular performances at tourist entertainment venues will accept work after the regular performances have finished, especially during the tourist high season and during important festivals. Aside from this, there are also ensembles who visit from other Provinces, such as Bangkok, Pathum Thani, Ang Thong, Suphanburi, Chiang Mai, Pattalun and Nakhon Sri Thammarat, who bring their own styles with them and allow for the continuation of cultural exchange.

\subsection{Current Problems with and Suggestions for Thai Musical Performing Arts in Phuket Province}

\subsubsection{Problems with Thai Music Ensembles}

The size of performance location is often incompatible with the ensembles and their instruments, either too large or too small. The performance area is also next to the tourist accommodation, causing the sounds to encroach upon the tourists' private space. There are no areas dedicated for storing the equipment and instruments or for 
costume change. Parking is also inconvenient and lengthens the preparation time of the performance, making the artists slow and late. Some establishments do not use sound and lighting, which make the performance incomplete and unappealing to the audience. The establishments do not allocate personnel to be responsible for the Thai music performance, which increases the work load of the ensemble. Occasionally, the entertainment venues break their agreements with the ensembles and there are natural obstacles to the performance. This reduces the performance quality.

There are not enough performers to fill the ensembles, causing the ensembles to fight over the artists. The ensemble paying the highest fee will attract the performers. Artists lack ability and experience and the ensembles have little time to train their members to an adequate level of expertise before performances. There is no sponsorship from educational institutes to allow students on professional Thai musical performance courses to join the ensembles for practice. Performers lack a sense of responsibility regarding time; they come late and do not practice. There are payment problems when the fees are paid late, as the ensembles are then unable to meet salary payments on time. The tourist entertainment venues also stop the performances in the low season and as a result the ensembles are unable to find regular employment, causing the need to find supplementary work elsewhere. The ensembles do not all have the same standards and as a result some ensembles are forced to accept low payments. These problems have an effect on the administration and management within the Thai music ensembles in Phuket Province

\subsubsection{Problems with Tourist Entertainment Venues That Employ Thai Music Ensembles}

There are many different levels of hotel in Phuket, which means there is a variation in hotel entertainment budgets. Small hotels with smaller budgets are unable to employ high quality Thai music ensembles. In times of natural disaster, political unrest and the low season, performances have to be cancelled until the high season. Nowadays, tourists come from many different countries and they have different preferences, meaning that the tourist entertainment venues must find a suitable compromise to meet all tastes. As some groups of tourists do not understand the culture, customs and traditions of Thailand, problems arise regarding inappropriate behavior shown by the tourists towards the performers, particularly female performers. Occasionally the tourists will try to play the instruments, without realizing the great respect held for them by the artists. Aside from this, there are also problems when ensembles perform longer than their allotted time, differently to the agreed format and use performers with bad manners or inappropriate behavior towards the tourists. If the performers do not connect with their performance, then the audience will become bored by the show. Boredom also occurs if there is no adaptation of the performance and no new shows.

\subsubsection{Problems with the Audiences}

Problems occur when the audiences do not understand the meanings of the performance and mood of the music because they have insufficient knowledge. This makes the audience become bored easily. The ensembles use instruments that are not appropriate for the place, especially with the use of instruments that are too loud. There is no use of information in the form of documents or other media that explain the performance to the audience. This causes a lack of awareness before the performance has begun.

\subsection{Suggestions for Solving the Problems with Thai Musical Performance in Phuket Province}

\subsubsection{Suggestions for Thai Music Ensembles}

The tourist entertainment venues should provide conveniences for the performers, such as parking spaces and accommodation. There must be a coordinator with knowledge of musical performance, including knowledge of Thai art culture, in order to properly coordinate between the ensemble and the tourist establishment. The tourist establishment must ensure that the ensemble is aware of the performance details beforehand in order to give them time to plan, prepare their instruments and manage their show. Ensembles in Phuket must set standards on the same scale in order to raise the level of Thai musical performance to equal that of international performance. At times when the tourist entertainment venues must stop holding performances, government institutions responsible for tourism should help the Thai music ensembles as much as they are able by providing work elsewhere. The results of the research found that using Thai musical performing arts in Phuket Province should be adapted to take one of five forms suitable for use in tourist entertainment venues: a) application of Thai music with indigenous music in Thailand; b) application of Thai music with international music; c) application of Thai music with sound; d) application of Thai music with acting; e) application of Thai music CDs with acting.

\subsubsection{Suggestions for Tourist Entertainment Venues that Employ Thai Music Ensembles}


Thai music ensembles in Phuket Province should have criteria for employment, including a standard fee and a special fee based on the event, as well as a clear ensemble performance format to give the tourist establishments before employment. When there is no work, especially during the low season, the ensembles should use the time to adapt their performances and create new shows for use in the next high season. There should be study of audience preferences to find accurate data that can be used in making the show meet audience demands. The music ensembles and employing entertainment venues must make employment contracts that are agreed upon by both parties. When one party breaks the contract, there must be a fine or option to cancel. Additionally, the ensembles must have a process for selecting performers, using performers according to their ability and adapting the performance to the event. There must be a variety of performances, both Thai and applied. There should also be data about each performance ready to present to the audience.

\subsubsection{Suggestions for Audiences}

Performers must connect with their performance and use their emotion to entertain the audience. Standardized equipment should be used that is ready for performance, so as to prevent mistakes. The performers must have good characteristics, behavior and readiness to perform. Each ensemble must practice their performances and use performers who are professional in order to make a complete and standardized show. Sound and light techniques must be used to help the performance and make the show more interesting. The performances must be varied, including both Thai and applied styles.

\section{Discussion}

\subsection{The History of Thai Music Ensembles at Entertainment Venues in Phuket Province}

With the increase of the tourist industry in Phuket Province, visitors came to the island from many different countries. These tourists thus had their own music and art preferences. In order to accommodate the tastes of the maximum number of visitors, Thai music ensembles have had to incorporate the styles of their audiences into their performances. This cultural exchange fits to the diffusion theory model of Franz Boas, whereby people either take their culture with them or outsiders enter their society and 'borrow' it (Chantachon, 2010). This also fits into the cultural diffusion theory of the German School, proposed by Wilheim Schmidt and Fritz Graebner. Their theory stated that humans do not usually create their own culture, rather using the cultures of their neighbors, an uninventive habit. This means that diffusion is inherent and similar traits will be found in different cultures. This shows that after Thai musical performance was brought to the province from Central Thailand, it was able to expand to all areas in Phuket Province where there were no obstacles. This is in agreement with the research of Prachum Bonnawm (1999), Narongrit Kongpin (1996) and Chayanit Panyasang (2005), who studied Piphat ensembles in Lampang Province, Piphat Mon culture and the music of the Tai Yai ethnic group, respectively. These three researchers concluded that the musical culture in their research areas was originally inherited from external societies.

There are important structures for Thai musical performance used in tourist entertainment venues in Phuket Province, which are divided into three roles. These are: a) the role of government institutions in Phuket; $b$ ) the role of private institutions; c) the role of Thai music ensembles. The structures relate to the idea of social functions posed by Bronislaw Malinowski, who stated that human needs must be met in three precise categories: basic biological and psychological needs, instrumental needs and symbolic needs (1944). Additionally, the existence of Thai musical performance on Phuket and its adaptation to the tastes of foreign audiences is a good example of Julian Steward's cultural ecology at work. First, as the natural tin reserves ran low, the society was forced to turn to tourism as its major source of income. Then with the increasing number of tourists, it was necessary to find ways to encourage these tourists to remain and utilize different entertainment venues, as well as promote Thai culture. As the Western styles began to infiltrate the culture, the next stage of development was to adapt the performances to meet the general tastes of the population. Therefore, as the communities depended on the environment, so the environment caused the alteration of society; cultural ecology at work (Steward, 1972).

\subsection{Current Problems with and Suggestions for Thai Musical Performing Arts in Phuket Province}

The problems and suggestions for their solution identified in this investigation correspond to the management theory of Wirat Ratnippawan (2013). The theory identified humans as animals that live together in families, tribes, communities, societies and countries. When humans live together in groups there are ways for the group to control and take care of one another so that there is fun and peace within the group. These conditions have evolved over time until the present day. This control and care is known as administration and the basis of this administration is knowledge and the arts, through the use of administrative resources such as people, money, objects and management. These resources are brought into various processes, so to efficiently achieve the defined objectives. 


\subsection{Applying Thai Musical Performing Arts to Promote Tourism in Phuket Province}

Adapted performances have started to be used by the ensembles of Phuket Province but there is no set format. The ensembles will adapt their performances according to the event by using a variety of different instruments, both Thai and indigenous. The indigenous instruments that are currently popular are mostly from Isan and include the pin, kaen and ponglang. In addition, international instruments and sound and lighting techniques are used to make the performances more interesting. Adaptation of Thai music in Phuket Province is creative work of culture that reveals lifestyle. The role of the performance is in connecting with the audiences to educate and impress. Thai musical performance is one symbol of Thailand that can be used as a medium to allow the audience to visualize and memorize the Thai cultural identity. These adaptations rely on a variety of aspects including customs and traditions in order to design a show that is appropriate for the society. Furthermore, these adaptations must preserve cultural roots so that they will not compromise the identity of Thai music.

\section{References}

Bonnawm, P. (1999). A study of community strength: A case study of the inheritance of the indigenous Ban Wong Piphat in Chompoo Sub-district, Mueang District, Lampang Province [in Thai]. Bangkok, Chulalongkorn University Press

Chantachon, S. (2010). Documents used for teaching the subject 1605902: Theories of culture and society [in Thai]. Maha Sarakham, Mahasarakham University.

Jantawanit, S. (2003). Theories of sociology [in Thai]. Bangkok, Chulalongkorn University Press.

Kongpin, N. (1996). The musical culture of Piphat Mon [in Thai]. Nakhon Pathom, Mahidol University.

Malinowski, B. (1944). A Scientific Theory of Culture and Other Essays [in Thai]. Chapel Hill, N. Carolina, The University of North Carolina Press.

Ministry of Culture. (2013). Vision, responsibility and strategy [in Thai]. Retrieved March 15, 2013, from $\mathrm{http} / / / \mathrm{www} . \mathrm{m}$-culture.go.th/index.php/th/เกี่ยวกับสำนักงาน-6/ยุทธศาสตร์-นโยบาย-และแผนงานด้านการศา สนา-ศิลปะ-วัฒนธรรม/วิสัยทัศน์-พันธกิจ-และยุทธศาสตร์.html

Office of the National Human Rights Commission of Thailand. (2007). Constitution of the Kingdom of Thailand. Retrieved March 15, 2013, from http://www.nhrc.or.th/2012/wb/img_contentpage_attachment/474_file _name_7532.pdf

Panyasang, C. (2005). The music of the Tai-Yai people [in Thai]. Nakhon Pathom, Mahidol University.

Poomputaworn, R. (2007). Phuket [in Thai]. Phuket, Blue Letin Company.

Pugan, C. (2006). The true essence of Thai music [in Thai]. Bangkok, Bannagit Publishers.

Ratnippawan, W. (2013). Concepts and meanings of management and administration [in Thai]. Retrieved March 15, 2013, from http://www.wiruch.com

Rungrueang, P. (2004). History of Thai Music [in Thai]. Bangkok, Thai Wattanapanich

RYT9. (2010). Concusions of the fourth quarter of the Thai economic outlook of 2009 and policies for 2010 [in Thai]. Retrieved March 15, 2013, from http://www.ryt9.com/s/cabt/800829

Steward, J. H. (1972). Theory of Culture Change: The Methodology of Multi-linear Evolution [in Thai]. Illinois: University of Illinois Press.

Tamwihan, S. (1997). Thai Musicals [in Thai]. Bangkok: Chulalongkorn University Press.

Wallipokom, S. (1992). Classical dance music with Siam economy and society [in Thai]. Bangkok, Rueankaew Publishers.

\section{Copyrights}

Copyright for this article is retained by the author(s), with first publication rights granted to the journal.

This is an open-access article distributed under the terms and conditions of the Creative Commons Attribution license (http://creativecommons.org/licenses/by/3.0/). 